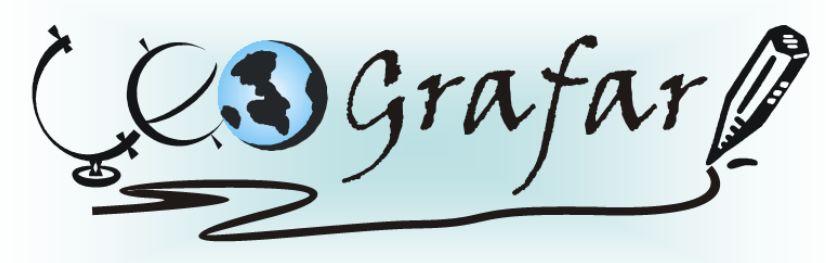

Revista Eletrônica do Programa de Pós-Graduação em Geografia - UFPR

\title{
O COMPERJ: MODELO DE DESENVOLVIMENTO HEGEMÔNICO E CONTRADIÇÕES NO ESPAÇO LOCAL (ITABORAÍ, RIO DE JANEIRO)
}

\author{
YANA DOS SANTOS MOYSÉS ${ }^{1}$
}

\begin{abstract}
Resumo: Esse artigo analisa o atual processo de instalação do Complexo Petroquímico do Rio de Janeiro (COMPERJ) no Município de Itaboraí, Região Metropolitana do Rio de Janeiro, afetando a Área de Proteção Ambiental de Guapimirim, sob os auspícios da contradição dos projetos de gestão dos territórios na localidade. O objeto de estudo desse trabalho é um exemplo das contradições entre os modelos de desenvolvimento socioespacial propostos por diferentes racionalidades de gestão dos territórios. O COMPERJ insere-se no território em questão trazendo consigo as concepções de desenvolvimento e sustentabilidade no seu discurso. O quê torna necessário, primeiramente, uma revisitação a esses conceitos/noções. Destaca-se nessa discussão o pensamento de autores que trazem a possibilidade de desenvolvimentos alternativos, salientando a plena participação dos indivíduos nos processos decisórios. Compreendemos que não existe apenas uma sustentabilidade e um desenvolvimento, mas sim sustentabilidades e desenvolvimentos de acordo com a cultura e a história de cada sociedade. A partir disso, uma análise crítica em relação à localização do pólo é feita, evidenciando as contradições existentes das realidades locais com o discurso do COMPERJ, já que como área submetida à legislação de Unidades de Conservação, os impactos tecnológicos do COMPERJ deverão gerar grandes danos à ordem ecossistêmica e social local. A pesquisa, dessa maneira, apontará para outras racionalidades e estratégicas que visem, principalmente, a justiça social e a qualidade de vida, questões que vêm sendo esquecidas e substituídas pelo avassalador poder da busca da eficiência econômica.
\end{abstract}

Palavras Chave: COMPERJ; Área de proteção ambiental de Guapimirim; contradições; desenvolvimentos; sustentabilidades.

\section{THE COMPERJ: MODEL OF HEGEMONIC MODERNIZATION AND CONTRADICTIONS IN LOCAL AREA (ITABORAÍ, RIO DE JANEIRO)}

\begin{abstract}
This article analyzes the current process of installing the Petrochemical Complex of Rio de Janeiro (COMPERJ) in the city of Itaboraí, Metropolitan Region of Rio de Janeiro, affecting the Environmental Protection Area of Guapimirim, under the auspices of the contradiction of management projects of territories in the locality. The object of study of this work is an example of the contradictions between the models of socio development proposed by different rationalities of management of territories. The COMPERJ inserts itself in this territory by bringing the concepts of development and sustainability in its speech. What makes necessary, firstly, one revisit to these concepts / notions. It is emphased in this discussion the ideas of authors who bring the possibility of alternative development, emphasizing the full participation of individuals in decision making processes. We understand that there is not only one development and one sustainability, but sustainabilities and developments in accordance with the culture and history of each society. From this, a critical analysis on the location of the pole is made, highlighting the contradictions existing between the local realities with the speech of COMPERJ, since as an area subjected to the law of Conservation Areas, the technological impacts of

\footnotetext{
${ }^{1}$ Mestranda no Programa de Pós-Graduação de Geografia da Pontifícia Universidade Católica do Rio de Janeiro. Bolsista CAPES. E-mail: yanasmoyses@hotmail.com
} 
COMPERJ may produce major damage to the ecosystem order and the social order in this area. The research points to other rationalities and strategies that aim primarily to social justice and quality of life, which have been forgotten and replaced by the overwhelming power of the search for economic efficiency.

Keywords: COMPERJ; Environmental Protection Area of Guapimirim; contradictions; developments; sustainabilities.

\section{INTRODUÇÃO}

O Complexo Petroquímico do Rio de Janeiro (COMPERJ) a ser instalado no Município de Itaboraí, Região Metropolitana do Rio de Janeiro, traz consigo, pelo seu Relatório de Impactos Ambientais (RIMA), concepções acerca de desenvolvimento, modernização e sustentabilidade que são difundidas pelo site da PETROBRÁS, pelos seus folhetins, pelo Estado, pela mídia e, inclusive, por ONGs que atuam no local. Nessas concepções, as contradições entre as potencialidades locais com o discurso modernizante do complexo são nítidas e devem ser analisadas cautelosamente para que projetos de desenvolvimento não continuem a ser implementados de maneira aleatória em relação às transformações socioespaciais dos grupos territorializados nos espaços.

É necessária, dessa maneira, primeiramente, uma revisitação das noções de desenvolvimento socioespacial e sustentabilidade. Destacam-se nessa discussão as concepções de desenvolvimento do economista brasileiro Celso Furtado (que muito contribuiu para as discussões acadêmicas e intelectuais sobre o desenvolvimento no Brasil, na segunda metade do século XX) e de autores das Ciências Sociais (notadamente os da Geografia) que trazem a possibilidade de discussões atuais para um repensar dos caminhos para "desenvolvimentos originais, criativos e inovadores do espaço brasileiro", salientando-se a plena participação dos indivíduos nos processos decisórios desses desenvolvimentos. Entende-se, assim, o caráter reflexivo da concepção de sustentabilidades para os desenvolvimentos de acordo com as perspectivas particulares dos territórios, que emanam cultura e história específicas e, portanto, outras racionalidades ligadas à ideia de qualidade de vida.

Em seguida, o COMPERJ será apresentado do ponto de vista da empresa, a partir de fontes dadas pela própria estrutura gestora do complexo, como: o Relatório de Impacto Ambiental (RIMA), o site, os folhetins e os documentos oficiais da Petrobrás, as ONGs locais e a mídia. 
Por último, então, averiguar-se-ão as concepções de desenvolvimento e sustentabilidade que o COMPERJ traz consigo, sendo feita uma análise críticoreflexiva em relação ao pólo, em que se abordarão as possíveis contradições existentes do projeto de desenvolvimento via COMPERJ com as realidades de gestão local, notadamente a partir da legislação das Unidades de Conservação (UCs).

\section{DESENVOLVIMENTOS E SUSTENTABILIDADES: UMA DISCUSSÃO REFLEXIVA ACERCA DE SUAS RACIONALIDADES NA ESFERA INTELECTUAL E DECISÓRIA, NO BRASIL CONTEMPORÂNEO}

\section{Os gestores, seus discursos e práticas}

Furtado (1962) afirmava que "acima de tudo devemos ter um plano de desenvolvimento econômico e social à altura de nossas possibilidades e em consonância com os anseios de nosso povo" (p.32). Naquele momento, o autor já nos alertava sobre a utilização de modelos de desenvolvimento fechados e préfabricados em outras realidades para as soluções dos nossos problemas. Acreditava que deveríamos buscar, em nossa realidade, uma política que orientasse o desenvolvimento do país.

Em 1978, o economista entendia que, em muitos lugares, o que incluía o Brasil, o processo de modernização significava ocidentalização, ou seja, o perecimento dos valores de nossa cultura. Da mesma maneira, Celso Furtado acreditava que a civilização industrial poderia ser lida como "uma crônica do avanço da técnica", ou seja, todas as formas criativas subordinadas à racionalidade instrumental (FURTADO, 1978, p.78).

Já na década de 1980, Celso Furtado entendia que o desenvolvimento deveria ser fundado na preservação da identidade cultural de cada uma das regiões que formam o país e em função de prioridades definidas pela própria coletividade. 0 autor salientava a importância do planejamento que, segundo ele, seria o único meio que permitiria a introdução da dimensão espacial (e, portanto, geográfica) no cálculo econômico. Dessa maneira, os custos ecológicos e sociais da aglomeração espacial 
das atividades produtivas, ignorados pelas empresas privadas e públicas, poderiam ser corrigidos (FURTADO, 1984).

Apesar de toda reflexão teórico-acadêmica do renomado economista, verificase, ainda na atualidade, que os discursos e as ações voltados para a modernização do território do Estado do Rio Janeiro pelos seus gestores públicos, como nos lembra Silva (2007), se apóiam na idéia "tradicional de desenvolvimento", ou seja, que a modernização da base técnico-produtiva, por si só, trará o bem-estar. Como tradicional, deve-se destacar a visão etapista de desenvolvimento de W. W. Rostow (1960) ${ }^{2}$ ainda prevalecente nas perspectivas de gestão pública, em que os espaços rurais, por exemplo, são entendidos como atrasados. Dessa maneira, este tipo de organização societária deveria ser extinta para que a modernidade fosse atingida, ou seja, como caminho condicional para uma sociedade industrial. Tal percepção ainda atinge os povos tradicionais como os das florestas, pescadores, caranguejeiros... que desenvolvem atividades artesanais e de subsistência.

A partir dessa visão etapista, as atividades industriais no território fluminense são pautadas apenas na produção, e não no pensamento da produção, o que é perceptível, por exemplo, no padrão petrolífero de Macaé e no nuclear de Angra do Reis. Verificam-se, de acordo com Silva (2006), articulações com grandes corporações e empresas de alta tecnologia e, com isso, mudanças nas características pré-estabelecidas dos locais a partir de processos técnico-científicos que remontam e re-significam os lugares (SILVA, 2006). Em outras palavras, desvalorizam as tradições locais e regionais em busca da "modernização" (SILVA, 2007).

Percebemos, portanto, entre os gestores do Estado do Rio de Janeiro, uma falta de racionalidade para a discussão dos custos sociais, ambientais, políticos...em longo prazo. Preconiza-se o pensamento em curto-prazo e, da mesma forma, interesses globais/ nacionais se sobrepõem aos interesses locais (FURTADO, 2007).

${ }^{2}$ Ver: ROSTOW, W.W. Chapter 2, "The Five Stages of Growth-A Summary. In: The Stages of Economic Growth: A Non-Communist Manifesto. Cambridge: Cambridge University Press, 1960. Disponível em: < http://www.mtholyoke.edu/acad/intrel/ipe/rostow.htm>. Acesso em 26 de abril de 2009. 
Ainda em 1984, Furtado criticava o centralismo político e defendia a autonomia regional. Com a Constituição de 1988 e a descentralização do poder, a escala subnacional foi valorizada, conquistando maior autonomia administrativa e financeira. Entretanto, no Brasil, segundo Rua (2002), a descentralização tributária e o fortalecimento dos municípios pode tanto representar a participação popular na gestão dos recursos, como privilegiar as oligarquias locais que serão fortalecidas com a entrada de recursos, podendo anular ou manipular a participação das comunidades locais. Exemplo disto são os diversos conselhos locais que existem formalmente para cumprirem as leis e garantirem a entrada dos recursos (RUA, 2002).

De uma maneira geral, percebemos em quais racionalidades se apóiam os gestores do território fluminense.

\section{Alternativas de projetos de gestão no território}

Retornando a Celso Furtado, descortinaremos os caminhos de possíveis gestões democráticas e participativas no território fluminense.

Furtado (1978) nos lembrava das ambigüidades inerentes à idéia de desenvolvimento, em que o mesmo conceito / noção é utilizado para processos históricos diferentes, salientando, ainda, que o processo de desenvolvimento não pode existir sem que haja a liberação criadora de um povo. O autor supracitado acredita que a "modernização" afastou-se das necessidades mais elementares da população. Dessa maneira, os obstáculos à passagem da simples modernização ao desenvolvimento cimentam-se na esfera social (FURTADO, 1984).

Em 1992, segundo Furtado, o principal desafio que se colocava no século XXI era:

...nada menos que mudar o curso da civilização, deslocar o seu eixo da lógica dos meios a serviço da acumulação, num certo horizonte de tempo, para uma lógica dos fins em função do bem-estar social, do exercício da liberdade e da cooperação entre os povos (FURTADO, 1992, p.75-76). 
O autor, dessa maneira, já nos adiantava, na época, o assunto a ser tratado na Conferência das Nações Unidas sobre Meio Ambiente e Desenvolvimento a ser realizado no Rio de Janeiro no mesmo ano. Acreditava que a civilização criada pela Revolução Industrial, na qual uma minoria dispõe dos recursos não-renováveis sem se preocupar com as gerações futuras do desperdiço que hoje realiza, levaria a grandes calamidades. Acrescenta, assim, que a principal tarefa para o novo século que se aproximava, seria o estabelecimento de novas prioridades para uma ação política que apontasse para uma nova concepção de desenvolvimento, posto ao alcance de todos os povos e que fosse capaz de preservar o equilíbrio ecológico.

$\mathrm{Na}$ busca do nosso desenvolvimento, deveríamos então assumir nossa situação história, conhecer nossa realidade, e não reproduzir o perfil daqueles que se auto-intitulam desenvolvidos. Ou seja, assumir nossa própria identidade (FURTADO, 1992).

Em outras palavras, interpretamos que nesse momento, Furtado (1992) ligava claramente a concepção de desenvolvimento à de sustentabilidade, pensado a partir da nossa realidade, satisfazendo as necessidades de nosso povo e, dessa forma, pela ação criativa dos homens e mulheres de nosso país. Sabemos que foi a partir da Conferência das Nações Unidas sobre Meio Ambiente e Desenvolvimento (Rio92) que o princípio de sustentabilidade tem sido concebido como um discurso científico e político internacionalmente (GUIMARÃES, 1997; MARQUARDT, 2006; PORTO-GONÇALVES, 2006).

Segundo Guimarães (1997), desde a Conferência do Rio (1992) a percepção predominante é de que os problemas do meio ambiente estão vinculados aos problemas do desenvolvimento. Entretanto, os atores promotores do desenvolvimento sustentável são os mesmos que constituem a base social do modelo dominante atual, ou seja, a lógica permanece a mesma, e os fundamentos econômicos do processo produtivo, consequentemente, também são os mesmos: capital, trabalho e recursos naturais. Dessa maneira, não é de se estranhar que o Banco Mundial tem sido o principal gestor financeiro de estratégia de desenvolvimento sustentável e o financiador da Agenda 21 (GUIMARÃES, 1997). 
Em outras palavras, o princípio de sustentabilidade é estritamente relacionado à lógica do mercado. Qualquer coisa só é sustentável quando se "auto-sustentar" economicamente. Contudo, diversas visões contrapõem essa ideia.

Guimarães (1997) entende que os problemas ocasionados pela desigualdade social e degradação ambiental não podem ser definidos como problemas individuais, já que constituem, de fato, problemas sociais. $\mathrm{O}$ autor acredita, então, ser impossível adquirimos signos de sustentabilidade sem que seja resolvida a imensa desigualdade no acesso e distribuição dos recursos naturais, econômicos e políticos, intra e entre nações. A partir disso, enumera em seu artigo algumas dimensões de sustentabilidades: planetária, ecológica, ambiental, demográfica, cultural, social, política e institucional (GUIMARÃES, 1997).

Leff (2001) trabalha com o princípio de incomensurabilidade para nos dizer da impossibilidade da redução dos processos ambientais a valores do mercado, ou seja, de se atribuir preços as externalidades ambientais. Acrescentando:

As influências culturais, sociais e institucionais na valorização das externalidades não coincidem com nenhum balanço contábil de custobenefício, nem é possível atribuir taxas de desconto para atualizar preferências e valorizações futuras (LEFF, 2001, p.70).

O mesmo autor, então, nos remete aos movimentos de resistência existentes que se colocam em oposição a essa apropriação capitalista da natureza e da cultura, levantando a questão da justiça ambiental, acreditando que não existem normas nem da economia nem da ecologia para equacioná-la. Dessa maneira, compartilha idéias como as de Acselrad e Leroy (1999), de que novos atores sociais devem fazer parte da condução de ações políticas, participando, assim, na tomada de decisões para a construção de outras racionalidades ${ }^{3}$ e de sustentabilidades democraticamente mais justas.

${ }^{3}$ Enrique Leff trabalha com a ideia de racionalidade ambiental. Segundo o autor, a partir da perspectiva dessa nova racionalidade, "os objetivos de equidade e sustentabilidade implicam abolir o domínio do mercado e do Estado sobre a autonomia dos povos". Dessa maneira, criaria condições para a "apropriação dos potenciais ecológicos" de cada uma das regiões de acordo com os valores culturais e interesses de cada comunidade (LEFF, 2001, p.77). 
Para isso, os autores mencionados acima, baseados em princípios de equidade social e diversidade cultural, afirmam que devem ser construídos desenvolvimentos alternativos que se posicionam em oposição à ideia historicamente construída que nos foi imposta de desenvolvimento, o qual poderia ser perfeitamente substituído por Ocidentalização ${ }^{4}$. Isto nos leva diretamente ao conceito de autonomia, o qual Souza (2001), baseado em Castoriadis, define muito bem, contrapondo-o ao de heteronomia. Segundo ele, a autonomia apresenta duas faces:

\begin{abstract}
...a individual (capacidade psicológica e possibilidade material e institucional efetiva de o indivíduo estabelecer fins para a sua existência e persegui-los de modo lúcido, em igualdade de oportunidades com os outros indivíduos da mesma sociedade) e a coletiva (presença de instituições sociais que garantam igualdade efetiva - e não apenas formal - de oportunidades aos indivíduos para a satisfação de suas necessidades e, muito especialmente, para a participação em processos decisórios relevantes na regulação da vida cotidiana) (SOUZA, 2001, p.159).
\end{abstract}

Em outras palavras, a autonomia de cada comunidade é a construção de outras racionalidades "de baixo para cima", ou seja, a partir da participação social inerente aos seus valores culturais e aos seus interesses, e não "de cima para baixo", com o domínio do mercado e do Estado sobre os povos, ditando as leis e as normas às sociedades (heteronomia). Contudo, como nos lembra Souza, devemos ter em mente que a conquista da autonomia é um processo, e que o diálogo uma vez buscado entre culturas distintas, não deve ser rejeitado, não se permitindo uma cultura enfraquecer ou modificar a cultura do outro (SOUZA, 2001).

Compreendemos, então, como Rua (2007), que não existe apenas "uma sustentabilidade" e "um desenvolvimento", mas sim, sustentabilidades e desenvolvimentos de acordo com a cultura e a história de cada sociedade.

Contudo, sabemos, também, que a questão não passa assim, apenas de uma coisa para outra, em que nos fechamos em culturas isoladas e os conflitos se acabam. Existem simultaneamente conexões entre o local e o global, de uma cultura

\footnotetext{
${ }^{4}$ Ver RUA, João. Desenvolvimento, espaço e sustentabilidades. In: RUA, João (org.) Paisagem, Espaço e Sustentabilidades: uma perspectiva multidimensional da geografia. Rio de Janeiro: PUCRio, 2007, p.143-194.
} 
com outra, e dentro de uma mesma comunidade há uma diversidade de atores sociais cujos interesses são quase sempre conflituosos

Nesse contexto, observou-se o fato de os gestores do Estado do Rio Janeiro privilegiarem a visão hegemonicamente aceita de desenvolvimento, contrapondo-se aos pensamentos dos autores aqui referenciados, tais como ao de Furtado (1984), que acreditava que o desenvolvimento requer também criatividade no plano político.

Segundo Souza (2003), as críticas se radicalizaram ao chamado "mito do desenvolvimento" nas últimas três décadas, rejeitando-se a própria ideia de desenvolvimento, como se essa referisse unicamente a uma ideia hegemônica de crescimento + modernização tecnológica, a ideologia capitalista. Entretanto, o autor afirma que a palavra desenvolvimento possa ser moldada conceitualmente de forma alternativa, defendendo a utilização do termo desenvolvimento socioespacial.

Acreditamos assim ser possível uma modernização fundada na qualidade de vida e na justiça social, a partir de desenvolvimentos alternativos, como os propostos pelos diversos autores a seguir: Souza (1996), Guimarães (1997), Acselrad e Leroy (1999), Leff (2001), Furtado (2007), Rua (2007), Silva (2007), entre outros. Esses autores salientam a necessidade de participação popular nos processos decisórios, o quê, em outras palavras, significa a plena participação dos indivíduos no processo de desenvolvimento.

Furtado (2007) afirma que o fator político é a esfera mais nobre das atividades criativas e que devemos, então, tomar gosto pelo exercício da imaginação para assim darmos continuidade à construção do Brasil. Assim sendo, Rua (2002) nos faz acreditar que o lugar seja o ponto de partida para modelos de desenvolvimento menos desiguais e excludentes, o que nos impele a buscar no planejamento e gestão dos espaços do Estado do Rio de Janeiro os interesses e as necessidades das populações locais, valorizando as suas tradições ao invés de supervalorizar os interesses nacionais (SILVA, 2006). Além disso, como Furtado (2007) preconiza em seus estudos, os custos socioambientais devem ser contabilizados em longo-prazo como pré-requisito para gestões mais democráticas no espaço. 
A partir disso, analisaremos o COMPERJ e sua inserção no estado, o qual tem como pano de fundo a aparente idéia de modernização acoplada ao desenvolvimento técnico-científico.

\section{COMPLEXO PETROQUÍMICO DO RIO DE JANEIRO (COMPERJ): APRESENTAÇÃO PELA FONTE GESTORA DA EMPRESA}

O Complexo Petroquímico do Rio de Janeiro (COMPERJ) é o maior empreendimento individual da história da Petrobras, com um investimento de $R \$ 15$ bilhões. Está previsto para entrar em operação em 2012. Além disso, constitui-se em uma das partes importantes do Programa de Aceleração do Crescimento - PAC ${ }^{5}$ lançado no inicio de 2006 pelo Governo Federal (RIMA-COMPERJ, 2007).

O Relatório de Impacto Ambiental (RIMA) do COMPERJ também prevê que o pólo irá gerar cerca de 200 mil empregos diretos, indiretos e efeito de renda em âmbito nacional. Além disso, evidencia que sua produção irá estimular a instalação de outras indústrias de bens de consumo na região de influência do pólo. Estudos da Fundação Getúlio Vargas estimam que 720 empresas irão se instalar na região até 2015 para produzirem plásticos (copos e sacos plásticos, embalagens de alimentos e de cosméticos brinquedos, fibras para a indústria têxtil e garrafas de refrigerantes e de água, assim como componentes para as indústrias montadoras de automóveis, eletrodomésticos), a partir da transformação dos produtos petroquímicos do COMPERJ.

Atualmente, o Brasil exporta óleo cru pesado e importa uma significativa quantidade de óleo leve. O pólo refinará 150 mil barris diários de petróleo pesado cru do campo de Marlim, Bacia de Campos. O projeto apresenta uma nova tecnologia que será utilizada pela primeira vez no Brasil e, consequentemente, poderá ser uma alternativa competitiva para promover o crescimento da indústria petroquímica no país (Ibidem).

\footnotetext{
${ }^{5}$ Segundo o site do Governo Federal, o PAC além de ser um programa de expansão do crescimento, é considerado um novo conceito de investimento em infra-estrutura, já que aliado a medidas econômicas tem o objetivo de estimular os setores produtivos e, ao mesmo tempo, levar benefícios sociais para todas as regiões do país (https://www.pac.gov.br/, Acesso em 15 de abril de 2009). Ver os investimentos do PAC no Estado do Rio de Janeiro: http://www.brasil.gov.br/pac/.arquivos/relatorioRJ_090409.pdf
} 
O RIMA acrescenta que a escolha da localização do pólo se deu devido á (ao): disponibilidade e facilidades da região, o que inclui o futuro Arco Metropolitano viabilizado pelo COMPERJ, ligando Itaboraí ao Porto de Itaguaí; melhor aproveitamento da logística existente; maior competitividade para cadeia produtiva; maior inclusão social para região (2007).

FIGURA 1: O COMPERJ E O ARCO METROPOLITANO NO CONTEXTO DA INTEGRAÇÃO REGIONAL.



Fonte: RIMA-COMPERJ (2007).

O Relatório sustenta ainda que o complexo não só proporcionará uma renovação econômica como ambiental, e que já deu início a um Corredor Ecológico que prevê o plantio de quatro milhões de mudas, acrescentando que a ideia é garantir que a implantação do empreendimento no local atenda aos princípios do desenvolvimento sustentável e da responsabilidade social.

Percebemos que o COMPERJ traz consigo, pelo RIMA, as ideias de desenvolvimento, modernização, desenvolvimento sustentável e responsabilidade social difundidas pelo site da Petrobras, pelos seus folhetins, pelo Estado, pela mídia e, inclusive, por ONGs que atuam no local. Entretanto, essas concepções, também, vêm sofrendo diversas críticas. 


\section{PROJETOS DE MODERNIZAÇÃO: UMA ANÁLISE CRÍTICA DO COMPLEXO PETROQUÍMICO DO RIO DE JANEIRO}

Neste momento, será realizada uma abordagem mais clara sobre as lógicas de concepção do COMPERJ como instrumento espacial de modernidade.

O Complexo Petroquímico do Rio de Janeiro (COMPERJ), como dito anteriormente, traz, inserido em seu RIMA, as concepções de modernização, desenvolvimento e sustentabilidade que serão justificadas como fundantes da decisão de alocação do pólo na RMRJ.

Numa perspectiva histórica, percebemos que o Rio de Janeiro passou nas últimas décadas por diversos episódios que afetaram a auto-estima da sua população: a transferência da capital do país para Brasília, a fusão autoritária dos Estados da Guanabara e o do Rio de Janeiro, a perda gradual da gestão sobre o capital privado para São Paulo, entre outros.

O Rio de Janeiro, o que inclui a sua capital, os demais municípios metropolitanos e o estado, como nos lembra Souza (2000), é marcado por uma mediocridade administrativa e um contexto subregional economicamente problemático, o que subtrai possibilidades de emergência desse estado no contexto político nacional. Assim sendo, o COMPERJ é interpretado como uma oportunidade de crescimento econômico, de "desenvolvimento" e de "modernidade" que interfere no sentimento da população, principalmente dos cariocas que assistem, de longe, as possíveis benfeitorias do complexo, mas não vivenciam diretamente as conseqüências socioespaciais (atuais e futuras) na região. E é dessa maneira que o RIMA o descreve:

O Estado do Rio de Janeiro tem hoje a possibilidade de reverter um processo de esvaziamento econômico que começou com a mudança da capital federal para Brasília, acentuou-se na fusão com a Guanabara e aprofundou-se com a fuga de investimentos, aumento da criminalidade e perdas ambientais no interior. Este empreendimento pode dar oportunidade de crescimento econômico de forma positiva para o estado (RIMACOMPERJ, 2007, p.7). 
Entretanto, a desterritorialização ${ }^{6}$ das comunidades que estão na área do COMPERJ, assim como a proximidade do complexo com o Mosaico da Mata Atlântica Central Fluminense (MMACF $)^{7}$, principalmente com a APA de Guapimirim, leva a questionamentos de diversas entidades da sociedade civil tais como os Conselhos Gestores das respectivas áreas, de comunidades locais, da Academia, entre outros ${ }^{8}$, em relação a localização do pólo.

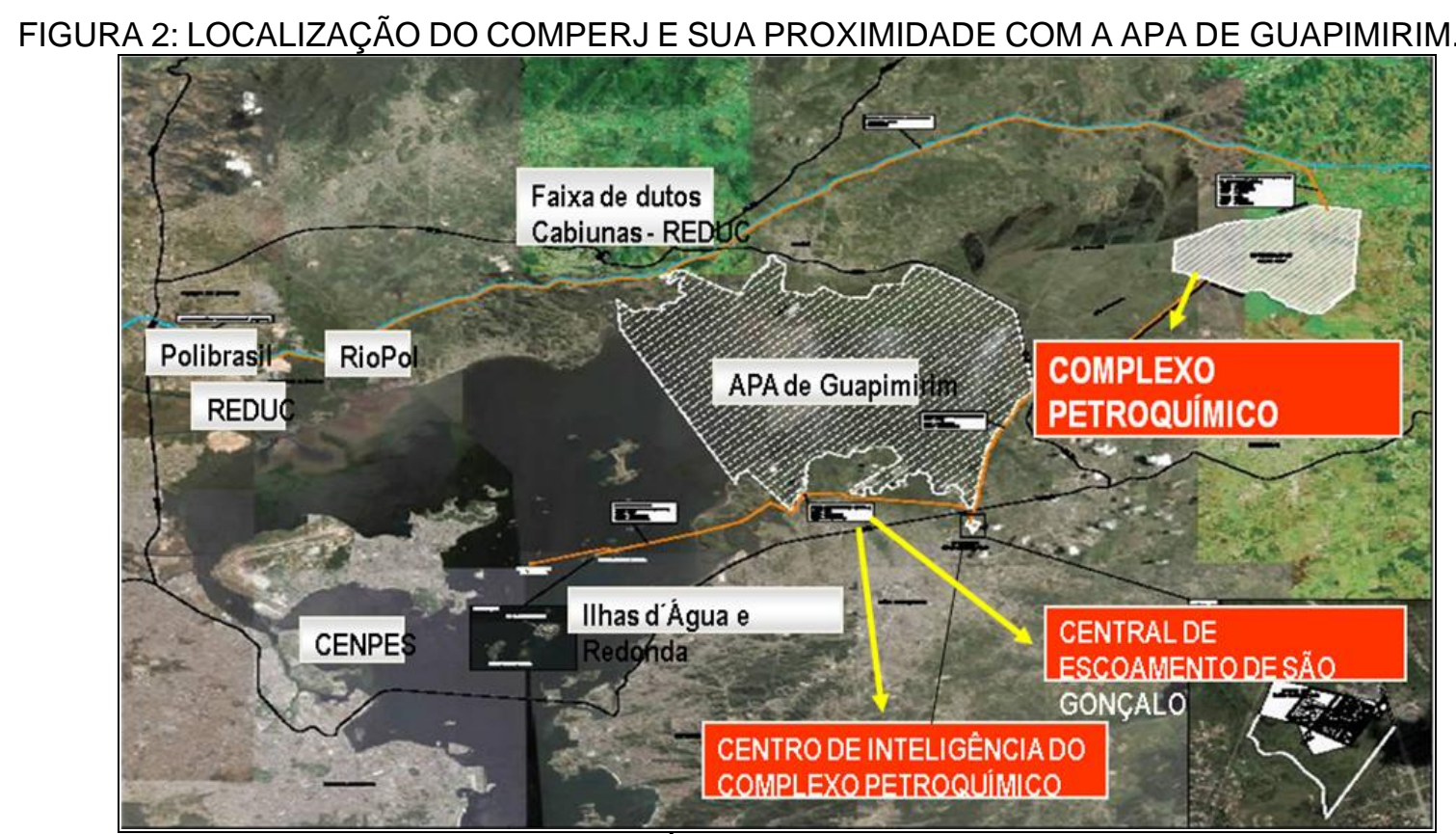

Fonte: ULTRA, BNDES e PETROBRÁS (agosto de 2007).

Nas reuniões realizadas pelo Conselho Gestor da APA de Guapimirim e pelo Conselho Gestor do Mosaico das Unidades de Conservação da Mata Atlântica

\footnotetext{
${ }^{6}$ Entende-se, de acordo com Haesbaert (2006), que a desterritorialização é um termo cada vez mais utilizado para detectar a precarização territorial dos grupos subalternos, ou seja, aqueles que vivenciam efetivamente uma perda de controle físico e de referências simbólicas sobre/a partir de seus territórios de vida. Compreendemos, tal como também afirma o mesmo autor que "o processo de desterritorialização não existe sem que este venha acompanhado de reterritorialização(ões)".

${ }^{7}$ O MMACF foi criado pela Portaria do Ministério do Meio Ambiente em dezembro de 2006 e reúne 22 Unidades de Conservação: 2 Reservas Biológicas, 3 Estações Ecológicas, 1 Monumento Natural, 4 Parques, 8 Áreas de Proteção Ambiental, 4 Reservas Particulares do Patrimônio Natural. Destas UCs, 5 são Federais, 7 Estaduais, 6 Municipais e 4 Privadas. Ocupando uma área de 233.710 hectares em 13 municípios (GIULIANI, 2007).

${ }^{8}$ GIULIANI, Gian Mario. As áreas naturais protegidas e a responsabilidade social e ambiental das empresas: o caso do Mosaico da Mata Atlântica Central Fluminense e do Comperj. Desenvolvimento e Meio Ambiente, n. 16, p. 21-37, jul./dez. 2007. Editora UFPR.
} 
Central Fluminense, em 01-10-2007 e 17-03-08, a localização do COMPERJ no ponto de vista da política ambiental foi considerada imprópria (GIULIANI, 2007).

Hoje, os manguezais da Baía de Guanabara estão restritos a uma área total de $81,50 \mathrm{Km}^{2}$, concentrada, principalmente, na APA de Guapimirim, que corresponde a uma área de $68,75 \mathrm{Km}^{2}$, com cerca de 14.000 hectares. A APA abrange os Municípios de Magé, Guapimirim, Itaboraí e São Gonçalo (AMADOR, 2001).

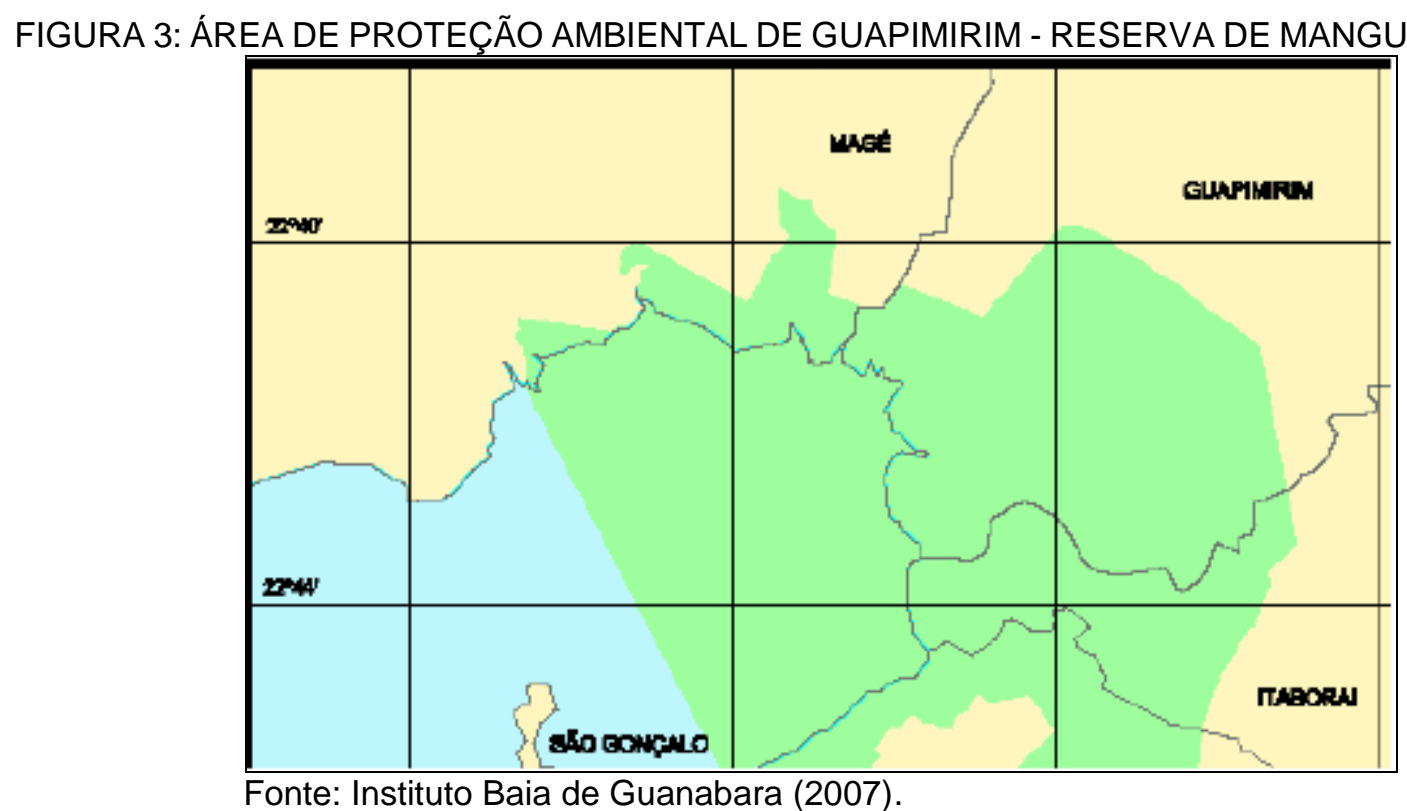

Esta APA $^{9}$ foi criada em 1984, pelo Decreto Federal no 90.225 (PLANO DE MANEJO DA APA DE GUAPIMIRIM, 2001), em resposta à primeira ação comunitária em defesa da Baía de Guanabara, que obrigou a DNOS (responsável pelas maiores transformações das bacias fluviais da baía) a desistir do projeto que criaria terrenos para as indústrias saneando a área compreendida pelos Rios

\footnotetext{
${ }^{9}$ De acordo com a Lei Federal n.o 9.985/00, SNUC - Sistema Nacional de Unidades de Conservação da Natureza, em seu artigo 15, a APA (Área de Proteção Ambiental) é definida: ... "como uma área em geral extensa; com um certo grau de ocupação humana; dotada de atributos abióticos, bióticos, estéticos ou culturais especialmente importantes para a qualidade de vida e o bem-estar das populações humanas, e que tem como objetivos básicos proteger a diversidade biológica, disciplinar o processo de ocupação e assegurar a sustentabilidade do uso dos recursos naturais; constituída por terras públicas ou privadas $\left(\$ 1^{\circ}\right)$; onde podem ser estabelecidas normas e restrições para a utilização da propriedade privada $\left(\S 2^{\circ}\right)$, condições para a realização de pesquisa científica e visitação pública, pelo seu órgão gestor, nas áreas públicas $\left(\S 3^{\circ}\right)$, e pelo seu proprietário, nas privadas $\left(\S 4^{\circ}\right)$; dispondo de um Conselho, presidido pelo órgão administrador e constituído por representantes dos órgãos públicos, de ONG (Organização Não Governamental) e da população residente (§ $\left.5^{\circ}\right)$ " (SNUC, 2003).
} 
Macacu-Guapi, Guaraí, Guaximdindiba, com seus canais de marés e manguezais associados (AMADOR, 1992). A APA de Guapimirim funciona como um berçário para milhares de espécies marinhas e é considerada, popularmente, como o "pulmão" da Baía de Guanabara, já que:

\begin{abstract}
...assegura a manutenção de condições naturais de trechos da baía, viabilizando a sua recuperação como ecossistema e garantindo a vida na baía, representada pela cadeia biológica constituída por microorganismos, crustáceos, moluscos, camarões, peixes e mamíferos (como os botos) (AMADOR, 2001, p. 137).
\end{abstract}

Dessa maneira, a vida marinha existente em toda baía é dependente desses manguezais, assim como eles são vitais para a manutenção dos estoques pesqueiros (KAMEL et al., 2004). A APA é também fundamental devido à produção de pescado com interesse comercial da Baía de Guanabara, o que evidencia uma grande importância econômica e social, principalmente no que diz respeito à quantidade de pessoas envolvidas nas atividades produtivas ${ }^{10}$.

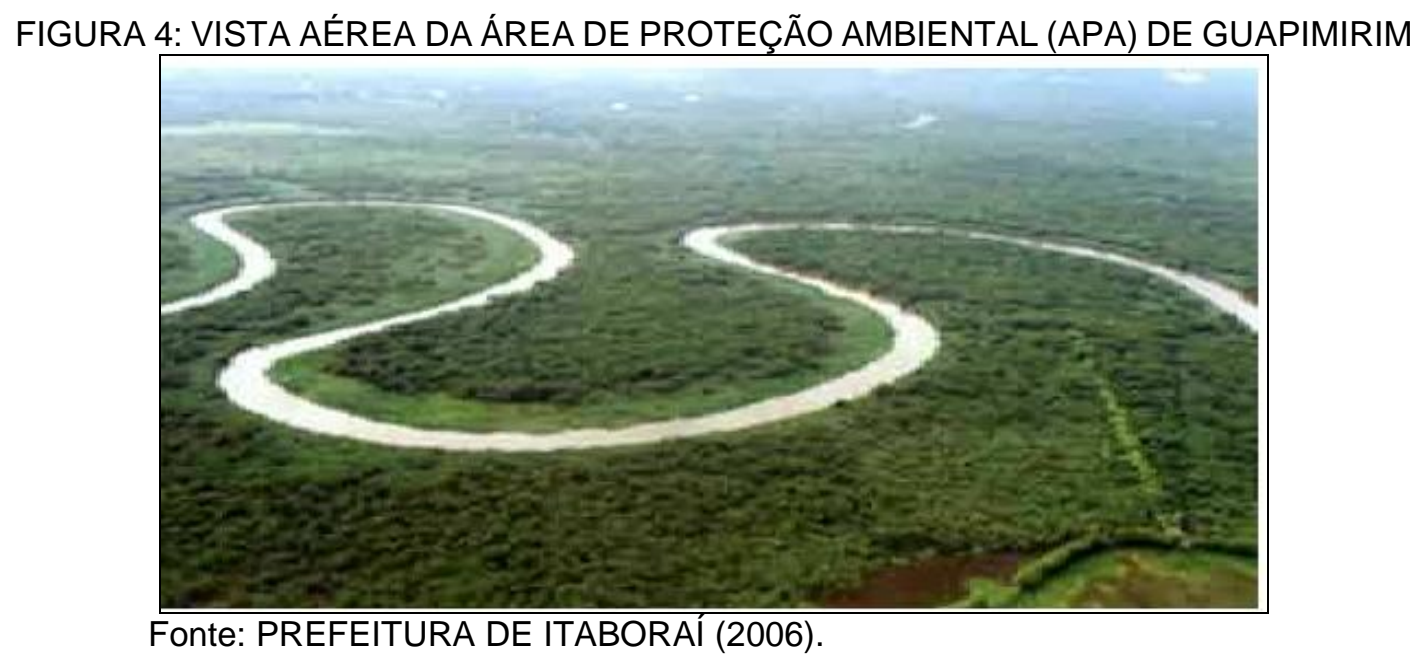

Com o intuito de proteger os manguezais da APA, e assim toda Baía de Guanabara, foi implantada, por iniciativa do IBAMA, uma Estação Ecológica dentro

${ }^{10}$ Em um trabalho realizado por JABLONSKI et al. (2006) a produção de pescado na Baía de Guanabara registrada, entre abril de 2001 e março de 2002, foi, aproximadamente, de 19.000 t, correspondente a um valor de 4,8 milhões de dólares. E a quantidade de pescadores envolvidos foi de, aproximadamente, 3700 pescadores. 
da APA de Guapimirim, pelo Decreto $s / n$ de 15 de fevereiro de 2006, a Estação Ecológica da Guanabara ${ }^{11}$. Esta é considerada a área mais preservada da Baía de Guanabara abrangendo os municípios de Itaboraí e Guapimirim (IBAMA, 2006).

Soares (2007) ${ }^{12}$ acrescenta outros pontos que também deveriam ser levados em conta quanto à localização do pólo petroquímico no Município de Itaboraí: a escassez de água da região e a fragilidade do ecossistema da Baía de Guanabara. Dessa maneira, o autor nos alerta que o COMPERJ e sua forte demanda por água, somado às outras indústrias que se instalarão no local e aos novos assentamentos urbanos, além do possível risco de contaminação por resíduos industriais, certamente comprometerão o futuro das bacias de drenagem da região. Salientando ainda, que a localização do pólo contraria o próprio Plano Diretor de Recursos Hídricos da Região Hidrográfica da Baia da Guanabara (PDRH-BG), que recomenda:

... impedir que áreas inundáveis ainda não ocupadas venham a ser urbanizadas, evitando assim futuros problemas. Recomenda-se delimitar estas áreas e criar legislação nos respectivos municípios tornando-as não urbanizáveis. ${ }^{13}$

Também, segundo o PDRH-BG, os Municípios de Itaboraí e Guapimirim são os piores em termos de disponibilidade de rede de esgoto, de água pluvial e de taxa de

${ }^{11}$ De acordo com SNUC - Sistema Nacional de Unidades de Conservação da Natureza - em seu artigo 9 : "A Estação Ecológica tem com objetivo a preservação da natureza e a realização de pesquisas científicas; A Estação Ecológica é de posse e domínios públicos, sendo que as áreas particulares incluídas em seus limites serão desapropriadas, de acordo com o que dispõe a lei $\left(\S 1^{\circ}\right)$;é proibida a visitação pública, exceto quando o objetivo educacional, de acordo com o que dispuser o Plano de Manejo da unidade ou regulamento específico( $\left(2^{\circ}\right)$; A pesquisa científica depende de autorização prévia do órgão responsável pela administração da unidade e está sujeita às condições e restrições por este estabelecidas, bem como àquelas previstas em regulamento(§3ํ); $\mathrm{Na}$ Estação Ecológica só podem ser permitidas alterações dos ecossistemas no caso de: I- medidas que visem a restauração de ecossistemas modificados, II- manejo de espécies com o fim de preservar a diversidade biológica, III- coleta de componentes dos ecossistemas com finalidades científicas; IVpesquisas científicas cujo o impacto sobre o meio ambiente seja maior do que aquele causado pela simples observação ou pela coleta controlada de componentes dos ecossistemas, em uma área correspondente a no máximo três por cento da extensão total da unidade e até o limite de um mil e quinhentos hectares $\left(\S^{\circ}\right)^{\prime \prime}$ (SNUC, 2003).

12 Mário Luiz Gomes Soares é oceanógrafo, professor da Faculdade de Oceanografia da Universidade do Estado do Rio de Janeiro e membro do Conselho Gestor da APA Guapimirim e do Conselho Consultivo do Mosaico da Mata Atlântica Central Fluminense.

${ }^{13}$ SOARES GOMES, Mario L. Responsabilidade socioambiental: a difícil transposição do "abismo "que separa a retórica da prática. Considerações sobre a proposta de localização do Comperj. Palestra - Desafios e conflitos na conservação e gestão de manguezais. UERJ, Rio de Janeiro. 2007. 
coleta e deposição final do lixo (SOARES, 2007). Segundo o próprio RIMA do COMPERJ, a construção do pólo aumentará a pressão nas áreas urbanas e urbanizáveis devido à atração de grupos populacionais em busca de trabalho. Entretanto, o mesmo delega a responsabilidade dos impactos aos órgãos públicos e às organizações da sociedade civil local (GIULIANI, 2007).

\begin{abstract}
Este impacto sobre o uso do solo e a infra-estrutura disponível, acontecerá se não houver medidas governamentais adequadas para absorver mão-deobra, ampliar a infraestrutura e controlar o uso do solo (...). A chegada de mão-de-obra para a fase de construção, vinda de outros municípios, poderá aumentar a ocupação irregular das áreas vazias em volta do COMPERJ, na ausência de controle do uso do solo pelo poder municipal (RIMACOMPERJ, p.103).
\end{abstract}

Deve-se destacar também a inclusão, no capítulo do meio ambiente da Constituição do Estado do Rio de Janeiro, das emendas referentes à Baía de Guanabara: Área de Preservação Permanente ${ }^{14}$ e Área de Relevante Interesse Ecológico $^{15}$ (AMADOR, 1992). Assim como, o relatório $\mathrm{PROBIO}^{16} 2000$, e sua revisão em 2006, do Ministério do Meio Ambiente que qualifica essa baía como área de alta importância biológica (SOARES, 2007). Além disso, visando a melhoria da sua qualidade ambiental, o Programa de Despoluição de Baía da Guanabara ${ }^{17}$ já

${ }^{14}$ De acordo com Código Florestal brasileiro (Lei 4.771 de 15/09/1965), incluído pela Medida Provisória ํㅡ 2.166-67, de 2001, Área de Preservação Permanente: área protegida nos termos dos arts. $2^{\circ}$ e $3^{\circ}$ desta Lei, coberta ou não por vegetação nativa, com a função ambiental de preservar os recursos hídricos, a paisagem, a estabilidade geológica, a biodiversidade, o fluxo gênico de fauna e flora, proteger 0 solo $e$ assegurar 0 bem estar das populações humanas. (http://www.planalto.gov.br/ccivil_03/LEIS/L4771.htm). Acesso em 30 de março de 2009.

${ }_{15}$ De acordo co SNUC, lei $n^{\circ} 9.985$, de 18 de Julho de 2000, no art.16, Área de Relevante Interesse Ecológico é uma área em geral de pequena extensão, com pouca ou nenhuma ocupação humana, com características naturais extraordinárias ou que abriga exemplares raros da biota regional, e tem como objetivo manter os ecossistemas naturais de importância regional ou local e regular o uso admissível dessas áreas, de modo a compatibilizá-lo com os objetivos de conservação da natureza (SNUC, 2003).

${ }^{16}$ Entre 1997 e 2000, o Projeto de Conservação e Utilização Sustentável da Diversidade Biológica Brasileira - PROBIO, componente executivo do Programa Nacional da Diversidade BiológicaPRONABIO, apoiou a realização de um estudo mediante ampla consulta para a definição de áreas prioritárias para conservação nos biomas brasileiros. Essas áreas foram reconhecidas pelo Decreto no. 5092, de 21 de maio de 2004 e instituídas pela Portaria no 126 de 27 de maio de 2004 do Ministério do Meio Ambiente. A portaria prevê a revisão periódica pela Comissão Nacional de Biodiversidade (CONABIO), em prazo não superior a dez anos, devido à dinâmica do avanço do conhecimento e das condições ambientais. (http://www.ibama.gov.br/zoneamentoambiental/areas_prioritarias/, Acesso em 30 de março de 2009).

${ }^{17}$ O Programa de Despoluição da Baia da Guanabara (PDBG), desenvolvido pelo governo do Estado do Rio de Janeiro, em conjunto com o Banco Interamericano de Desenvolvimento (BID) e o governo japonês, iniciado em 09 de março de 1994 é constituído por um conjunto de ações multidisciplinares 
consumiu bilhões de reais, o qual tem como premissa a redução das descargas de esgotos domésticos e industriais para esse ambiente (GIULIANI, 2007).

Por último, lembra-se aqui a importância da APA de Guapimirim para as comunidades que vivem em seus arredores, como é o caso da Comunidade de Itambi ${ }^{18}$. A comunidade, além de tirar sua subsistência seja pela cata de caranguejo, siri e pela pesca de robalo ou outros peixes, também possuí os seus modos de vida adaptados à região, assunto que se verifica no próprio RIMA-COMPERJ ao acrescentar que os manguezais da APA (...) "fornecem o sustento para diversas comunidades que recolhem animais" (RIMA-COMPERJ, 2007, p.67-68.).

Entretanto, segundo o Parecer Técnico 52/2007 APA-Guapimirim, 13 de dezembro de 2007, essa comunidade será desterritorializada para a construção de uma estrada principal de acesso e de outros acessos secundários que serão construídos e/ou recuperados para viabilizar o transporte de equipamentos e matéria-prima até o COMPERJ.

Pela figura a seguir ( $n^{\circ}$ ), observamos que o território onde, atualmente, os caranguejeiros vivem (contorno amarelo), servirá, em parte, para as obras do Arco Rodoviário do Rio de Janeiro. O contorno verde da figura, por sua vez, indica o local para onde a comunidade será realocada ${ }^{19}$, afastando-a dos mangues e dos rios pela Rodovia BR-493 RJ, que será um segmento do Arco Rodoviário (GIULIANI, 2007).

que compreendem obras, bens e serviços, relativas a intervenções nas áreas de esgotamento sanitário, abastecimento de água, coleta e destinação final de resíduos sólidos, drenagem de águas pluviais, dragagem de rios e lagoas, controle ambiental e mapeamento digital, visando à redução dos níveis de poluição da Bacia Hidrográfica da Baía de Guanabara (http://www.cedae.rj.gov.br/raiz/080.ASP). Acesso em 30 de março de 2009.

${ }^{18}$ A Comunidade de Itambi está localizada em Itambi, distrito do Município de Itaboraí, situado na Região Metropolitana do Rio de Janeiro, na parte leste da Baía de Guanabara. Itambi é a única área do município que tem ligação com a baía, localizando-se no chamado "Recôncavo da Guanabara".

${ }^{19}$ Termo utilizado no Parecer Técnico 52/2007, APA - Guapimirim em 13 de dezembro de 2007. 
FIGURA 5: IMAGEM DE SATÉLITE DA ÁREA EM ESTUDO (TRECHO DO MUNICÍPIO DE ITABORAÍ, RIO DE JANEIRO)
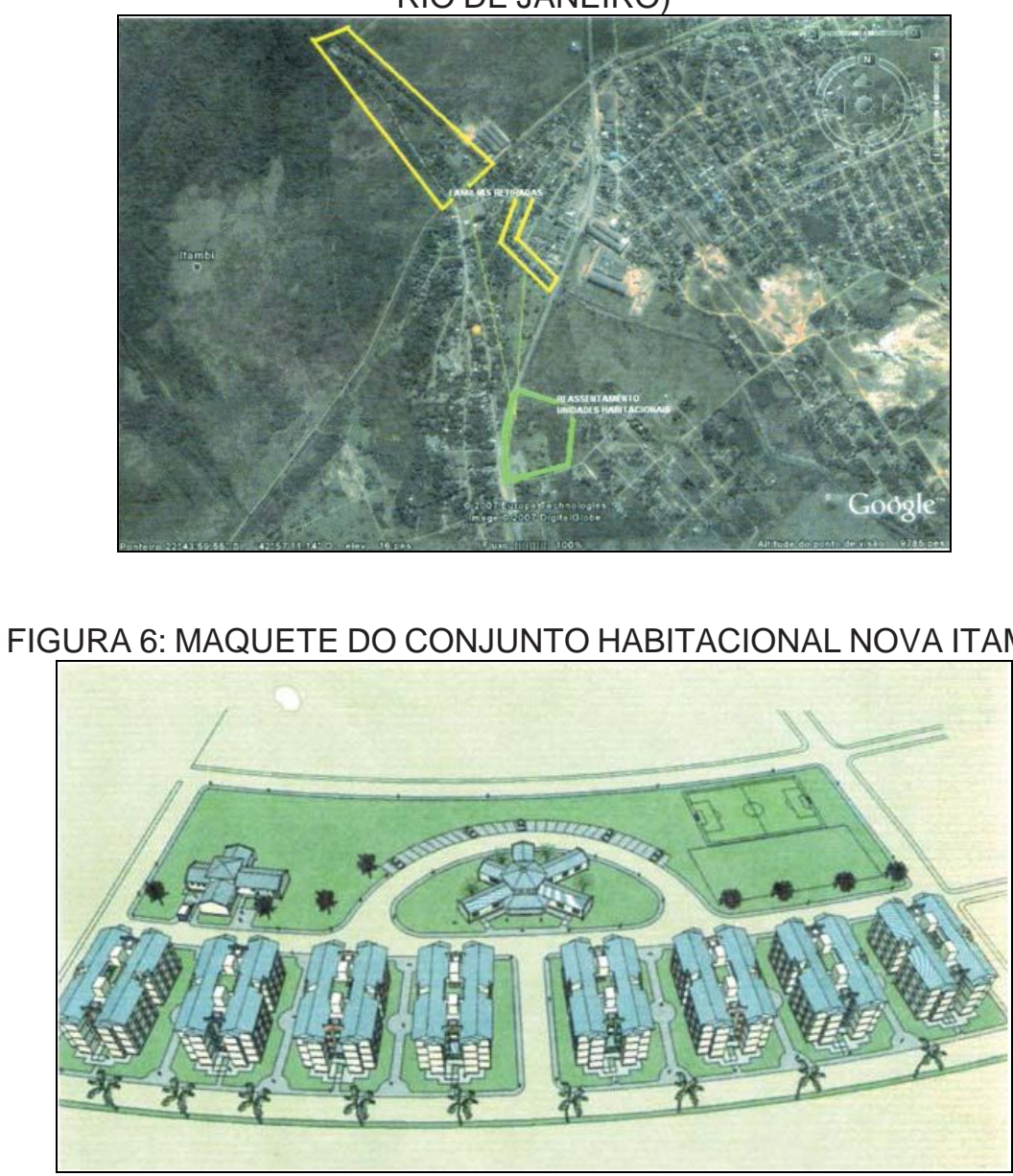

FONTE: Parecer Técnico 53/207 Apa-Guapimirim, 13 de dezembro de 2007.

Observamos pela figura acima, que a comunidade irá residir em apartamentos do Conjunto Habitacional Nova Itambi ${ }^{20}$, e não em casas como moram atualmente. No mesmo documento destacamos:

Segundo a presidente da Associação de moradores da Bacia, a maioria das pessoas está satisfeitas com a implantação do projeto, pois trará uma boa qualidade de vida para todos, haverá uma recuperação ambiental (como cita o projeto) (...).

Fomos informados de que apenas uma minoria de moradores está insatisfeita, isto é, são contrários a residir em apartamentos como prevê o projeto. (p.2)

${ }^{20}$ Nome dado pelo Parecer Técnico 52/2007 APA- Guapimirim em 13 de dezembro de 2007, ao local em que a população deverá residir. 
Entretanto, constatamos nos depoimentos em uma visita realizada no dia 13 de outubro de 2008, que os moradores da Bacia de Itambi careciam de informações. Alegaram que não foram consultados anteriormente e apenas comunicados que seriam transferidos do local.

Assim, como recorrente no território fluminense, as audiências públicas novamente servem estritamente para comunicar as decisões e a aparente abertura da participação da sociedade civil e da população diretamente envolvida em projetos de modernização é basicamente formal, ainda muito distante de projetos de gestão participativa.

De uma maneira geral, observa-se que o COMPERJ incorpora todos os prérequisitos que os gestores do Estado se apóiam: visão em curto prazo, interesses globais sobrepondo-se aos interesses locais, racionalidade estritamente técnicocientífica, assim como outros anteriormente já descritos.

O COMPERJ, a partir dessa análise, se enquadra perfeitamente nos discursos dos gestores do Estado do Rio de Janeiro e se distancia das concepções de desenvolvimento e sustentabilidade, já aqui defendidas, que acreditamos serem os caminhos de possíveis gestões democráticas e participativas no território.

\section{CONSIDERAÇÕES FINAIS}

Souza (2000) nos lembra criticamente que processos tal como o da implantação do COMPERJ são denominados de "desenvolvimento urbano", enfatizando a visão estreita e comumente aceita acerca dessa noção, restrita, de maneira primária, à modernização da base técnico-produtiva sem levar em conta os custos sociais e ambientais, repartindo-se desigualmente, os ônus e bônus entre as classes e grupos sociais. $\mathrm{O}$ autor ainda salienta que as vítimas da segregação socioespacial são as que mais sofrem com, o que ele denomina, de "a vingança das forças da natureza" (SOUZA, 2000, p.120).

Analogicamente ao pensamento do autor supracitado, já podemos perceber os primeiros reflexos da instalação do COMPERJ na transformação do território em questão no que diz respeito à repartição desses custos. Em um olhar inicial, dentre 
as primeiras vítimas desse "desenvolvimento" inclui-se a Comunidade de Itambi, perceptivelmente destinada a compartilhar os custos sociais e ambientais, ou seja, os ônus, e em primeiro momento, com perspectiva reduzida de inserção nessa nova lógica territorial.

Da mesma forma, pensamos como Furtado (1984), o qual dizia que deveríamos prevenir a desertificação cultural e humana de áreas economicamente frágeis, salientando-se que a racionalidade econômica refere-se a um tempo relativamente curto e que ignora os custos sociais e ecológicos das atividades produtivas e das grandes aglomerações humanas. De uma maneira geral, a lógica do COMPERJ, pelo que foi até aqui abordado, adere pontos essenciais que Furtado nos alertava para prevenir.

A instalação do COMPERJ é assim um exemplo claro das contradições entre os modelos de desenvolvimento socioespacial. A contradição existente das realidades locais com o discurso do COMPERJ nos parece evidente até o presente momento.

Assim sendo, devemos buscar nas contradições dos discursos oficiais dos gestores do território fluminense, nos quais os projetos modernizadores não condizem com as realidades dos lugares, resistências que contribuam na rediscussão de questões voltadas para estratégicas políticas que visem à efetiva justiça social (SILVA, 2007).

O Estado não pode ser apenas um gestor do cientificismo e da produtividade, mas sim um patrocinador da discussão sobre a primazia do lucro acima da qualidade de vida da sociedade. Acreditamos que só assim possamos ter sucesso nos projetos de gestão do território fluminense, e a geografia, com sua tradição holística e integração na análise espacial, torna-se imprescindível na contribuição desse debate. 


\section{REFERÊNCIAS BIBLIOGRÁFICAS}

ACSELRAD, Henri; LEROY, Jean-Pierre. Novas Premissas de Sustentabilidade Democrática. Rio de Janeiro: Projeto Brasil Sustentável e Democrático. FASE, 1999.

AMADOR, Elmo da Silva. Roteiro de visita à Baía de Guanabara. In: Educação Ambiental: especialização e capacitação em educação para gestão ambiental. Vol. II. Rio de Janeiro: Gráfica UERJ, 2001, p.127-147.

Baía de Guanabara: um balanço histórico. IN: ABREU, Maurício de Abreu (org.). Natureza e Sociedade no Rio de Janeiro. Rio de Janeiro: Biblioteca Carioca. 1992, p.201-258.

CEDAE [online]. Disponível em: <http://www.cedae.ri.gov.br/raiz/080.ASP>, Acesso em 30 de março de 2009.

FURTADO, Celso. O Capitalismo Global. 7. ed.São Paulo: Paz e Terra, 2007.

Brasil: a construção interrompida. Rio de Janeiro: Paz e Terra, 1992.

e Terra, 1984.

Cultura e Desenvolvimento em época de crise. 2.ed. Rio de Janeiro:Paz

Criatividade e Dependência na Civilização Industrial. São Paulo: CÍRCULO DO LIVRO S.A., 1978.

A Pré- Revolução Brasileira. Rio de Janeiro: Fundo de Cultura, 1962.

GIULIANI, Gian Mario. As áreas naturais protegidas e a responsabilidade social e ambiental das empresas: o caso do Mosaico da Mata Atlântica Central Fluminense e do Comperj. Desenvolvimento e Meio Ambiente, n. 16, p. 21-37, jul./dez. 2007. Editora UFPR.

GOVERNO FEDERAL [online]. Disponível: <http://www.planalto.gov.br/ccivil_03/LEIS/L4771.htm>, Acesso em 30 de março de 2009.

GOVERNO FEDERAL- PAC [online]. Disponível: <https://www.pac.gov.br/>, Acesso em 15 de abril de 2009.

GUIMARÃES, Roberto P. Desenvolvimento Sustentável: da retórica à formulação de políticas públicas. In: BECKER, Berta e MIRANDA, Mariana (orgs.). A Geografia Política do Desenvolvimento Sustentável. Rio de Janeiro: Ed. UFRJ, 1997, p.1344.

HAESBAERT, Rogério. O mito da desterritorialização: Do "Fim dos Territórios" à Multiterritorialidade. 2. Ed. Rio de Janeiro: Bertrand Brasil, 2006.

IBAMA [online]. Disponível: <http://www.ibama.gov.br/zoneamentoambiental/areas_prioritarias/>, Acesso em 30 de março de 2009. 
JABLONSKI, S.; AZEVEDO, A.F.; MOREIRA, L.H.A. Fisheries and Conflicts in Guanabara Bay, Rio de Janeiro, Brasil. In: Brasilian Archives of Biology and technology. 2006. Vol.49, o1:p.79-91.

KAMEL, M.; AMARAL, S.; SOARES, M.L.G. Imagens CCD/CBERS e TM/Landsat para análise multi-temporal de manguezais no Nordeste brasileiro. Um estudo no litoral do Estado do Ceará. In: Anais XII Simpósio Brasileiro de Sensoriamento Remoto, Goiânia, Brasil, INPE. 2005, p.979-986.

LEFF, Enrique. A reapropriação social da natureza. In: Saber Ambiental. Petrópolis: Vozes, 2001.p.65-82.

Ética Ambiental e Direitos Culturais. In: Saber Ambiental. Petrópolis: Vozes, 2001.p.83-95.

MMA/IBAMA, Plano de Manejo da Área de Proteção Ambiental de Guapi-Mirim. 2001 [CD-Rom]

PORTO-GONÇALVES, Carlos Walter. A globalização da natureza e a natureza da globalização. Rio de Janeiro: Civilização Brasileira, 2006.

PREFEITURA DE ITABORAÍ. [online]. Disponível: $<$ http://www.itaborai.ri.gov.br/prefeitura/legislação/cadernos-itadados.pdf>, Acesso: setembro 2007.

PREFEITURA DE SÃO GONÇALO [online]. Disponível: <http://www.saogoncalo.rj.gov.br>, Acesso: setembro 2007.

RUA, João. Desenvolvimento, espaço e sustentabilidades. In: RUA, João (org.) Paisagem, Espaço e Sustentabilidades: uma perspectiva multidimensional da geografia. Rio de Janeiro: PUC-Rio, 2007, p.143-194.

Urbanidades e Novas Ruralidades no Estado do Rio de Janeiro: Algumas considerações teóricas. In: MARAFON, Glauco José; RIBEIRO, Marta Foeppel (orgs.). Estudos de Geografia Fluminense.Rio de Janeiro: Livraria e Editora Infobook Ltda.2002, p.27-42.

Urbanização em áreas rurais no estado do Rio de Janeiro. In: MARAFON, Glauco José; RIBEIRO, Marta Foeppel (orgs.). Estudos de Geografia Fluminense. Rio de Janeiro: Livraria e Editora Infobook Ltda. 2002, p.43-69.

SILVA, Augusto César Pinheiro da. Discursos e práticas institucionais no estado do Rio de Janeiro: paradoxos organizacionais na modernização do espaço rural fluminense.In: RUA, João (org.). Paisagem, Espaço e Sustentabilidades: uma perspectiva multidimensional da Geografia. Rio de Janeiro: Editora PUC, 2007, p.237-284.

As estratégias de modernização do espaço rural fluminense: técnica, planejamento e gestão no campo do Rio de Janeiro. In: Revista Eletrônica CampoTerritório: Revista de Geografia Agrária, vol.1, n 2, 2006, p.92-122. 
SISTEMA Nacional de Unidade de Conservação da Natureza - SNUC: lei no 9.985, de 18 de julho de 2000; decreto $n^{\circ}$ 4.340, de 22 de agosto de 2002. 3. ed. aum. Brasília: MMA/SBF, 2003.52p.

SOUZA, Marcelo Lopes de. ABC do desenvolvimento urbano. Rio de Janeiro: Bertrand Brasil, 2003.

Território do Outro, problemática do mesmo?O princípio da Autonomia e a superação da dicotomia Universalismo Ético versus Relativismo Cultural. In: ROSENDAHL, Zeny\& CORRÊA, Roberto Lobato (orgs.). Religião, Identidade e Território. Rio de Janeiro: EDUERJ, 2001, p.145-176.

."Desenvolvimento urbano" e impactos ambientais nas metrópoles brasileiras. In: SOUZA, Marcelo Lopes. O Desafio Metropolitano-um estudo sobre a problemática socioespacial nas metrópoles brasileiras. Rio de Janeiro: Bertrand Brasil, 2000, p.118-125.

."How large is too large?" O que o tamanho tem a ver com os problemas do Rio de Janeiro e de São Paulo? In: SOUZA, Marcelo Lopes. O Desafio Metropolitano- um estudo sobre a problemática socioespacial nas metrópoles brasileiras. Rio de Janeiro: Bertrand Brasil, 2000, p.312-317.

Ática, 1996.

Urbanização e desenvolvimento no Brasil Atual.Série Princípios, Editora

RIMA-COMPERJ Petrobras- Concremat Engenharia [online]. Disponível em: $<$ http://www2.petrobras.com.br/ Petrobras/ portugues/pdf/rima.pdf $>$. [ Acesso em 2009]

ROSTOW, W.W. Chapter 2, "The Five Stages of Growth-A Summary. In: The Stages of Economic Growth: A Non-Communist Manifesto. Cambridge: Cambridge University Press, 1960. Disponível em: < http://www.mtholyoke.edu/acad/intrel/ipe/rostow.htm>. Acesso em 26 de abril de 2009.

\section{OUTRAS FONTES:}

Serviço Público Federal - Ministério do Meio Ambiente - APA de Guapimirim. Parecer Técnico 53/2007. Guapimirim, 13 de dezembro de 2007.

SOARES GOMES, Mario L. Responsabilidade socioambiental: a difícil transposição do "abismo" que separa a retórica da prática. Considerações sobre a proposta de localização do Comperj. Palestra- Desafios e conflitos na conservação e gestão de manguezais. UERJ, Rio de Janeiro. 2007.

(Recebido em agosto/2009. Aceito em novembro/2009) 